\title{
Relationships between nutrition screening checklists and the health and well-being of older Australian women
}

\author{
Amanda J Patterson ${ }^{1, *}$, Anne F Young ${ }^{1}$, Jennifer R Powers ${ }^{1}$, Wendy J Brown ${ }^{2}$ and \\ Julie E Byles ${ }^{3}$ \\ 'Research Centre for Gender and Health, University of Newcastle, University Drive, Callaghan, NSW 2308, \\ Australia: ${ }^{2}$ School of Human Movement Studies, University of Queensland, St. Lucia, QLD 4072, Australia: \\ ${ }^{3}$ Centre for Clinical Epidemiology and Biostatistics, University of Newcastle, University Drive, Callaghan, \\ NSW 2308, Australia
}

Submitted 5 March 2001: Accepted 30 May 2001

\begin{abstract}
Objectives: To examine associations between nutrition screening checklists and the health of older women.

Design: Cross-sectional postal survey including measures of health and health service utilisation, as well as the Australian Nutrition Screening Initiative (ANSI), adapted from the Nutrition Screening Initiative (NSI).

Setting: Australia, 1996.

Subjects: In total, 12939 women aged 70-75 years randomly selected as part of the Australian Longitudinal Study on Women's Health.

Results: Responses to individual items in the ANSI checklist, and ANSI and NSI scores, were associated with measures of health and health service utilisation. Women with high ANSI and NSI scores had poorer physical and mental health, higher health care utilisation and were less likely to be in the acceptable weight range. The performance of an unweighted score (TSI) was also examined and showed similar results. Whereas ANSI classified 30\% of the women as 'high-risk', only $13 \%$ and $12 \%$ were classified as 'high-risk' by the NSI and TSI, respectively. However, for identifying women with body mass index outside the acceptable range, sensitivity, specificity and positive predictive values for all of these checklists were less than $60 \%$.

Conclusions: Higher scores on both the ANSI and NSI are associated with poorer health. The simpler unweighted method of scoring the ANSI (TSI) showed better discrimination for the identification of 'at risk' women than the weighted ANSI method. The predictive value of individual items and the checklist scores need to be examined longitudinally.
\end{abstract}

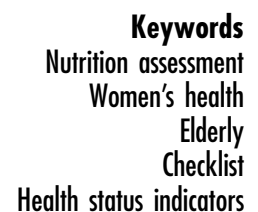

Health status indicators
Numerous studies have described links between malnutrition in older populations and increased levels of morbidity, and poor or delayed recovery from illness ${ }^{1-6}$. However, it is difficult to define malnutrition precisely, and its prevalence among older people varies according to how it is defined and the population under investigation. In the United States, the United Kingdom and Australia, it has been estimated that up to $40 \%$ of over 60 year olds living independently in the community may be suffering from some degree of malnutrition ${ }^{6-8}$. The prevalence is thought to be higher among the institutionalised $^{9}$ and hospitalised elderly ${ }^{6}$. In recognition of the fact that good nutrition has major potential for improving longevity and quality of life among older people, nutritionists in the United States developed the Nutrition Screening Initiative (NSI).
The NSI is a three-level screening and diagnosis programme, whereby older persons living in the community, or their carers, complete a checklist to determine their requirements for further nutritional assessment. A moderate or high score on the checklist is meant to guide consumers to speak with their health provider who then performs the second-level screen which assesses height, weight and weight changes, and briefly reviews eating habits, functional and socio-economic status. The third level is diagnostic and involves anthropometric and biochemical assessment ${ }^{10}$.

The NSI checklist was developed from data provided by 749 participants in the New England Elders Dental Study, which included 14 items previously found to be associated with nutritional well-being of older people ${ }^{11}$. Regression analysis was used to determine effect sizes for 
Table 1 Australian Nutrition Screening Initiative (ANSI) and Nutrition Screening Initiative (NSI) items and their weights

\begin{tabular}{|c|c|c|c|c|c|c|}
\hline \multicolumn{3}{|c|}{ Item number and question asked in survey } & \multicolumn{2}{|c|}{$\begin{array}{l}\text { NSI item effect } \\
\text { size for outcome criteriał }\end{array}$} & \multicolumn{2}{|c|}{$\begin{array}{l}\text { Allocated } \\
\text { weights for }\end{array}$} \\
\hline \multicolumn{2}{|c|}{ ANSI questions $(n=12)$} & NSI questions $(n=10)$ & $\begin{array}{l}\text { Nutrition } \\
\text { adequacy }\end{array}$ & $\begin{array}{l}\text { Perceived } \\
\text { health }\end{array}$ & NSI & ANSI§ \\
\hline 1 & $\begin{array}{l}\text { I have an illness or condition that made me } \\
\text { change the kind and/or amount of food I eat }\end{array}$ & Equivalent & -0.02 & $0.31^{*}$ & 2 & 2 \\
\hline 2 & I eat at least 3 meals a day & I eat fewer than 2 meals per day & $0.52^{*}$ & 0.02 & 3 & $\mathrm{No}=3$ \\
\hline 3 & I eat fruit or vegetables most days \} & I eat few fruits or vegetables, & & & & $\mathrm{No}=2$ \\
\hline 4 & I eat dairy products most days $\quad \int$ & or milk products & $0.40^{\star}$ & 0.06 & 2 & $\mathrm{No}=2$ \\
\hline 5 & $\begin{array}{l}\text { I have } 3 \text { or more glasses of beer, wine or } \\
\text { spirits almost every day }\end{array}$ & Equivalent & 0.07 & 0.16 & 2 & 3 \\
\hline 6 & $\begin{array}{l}\text { I have } 6 \text { to } 8 \text { cups of fluids (e.g. water, juice, } \\
\text { tea or coffee) most days }\end{array}$ & - & - & - & - & No $=1$ \\
\hline 7 & $\begin{array}{l}\text { I have teeth, mouth or swallowing problems } \\
\text { which make it hard for me to eat }\end{array}$ & $\begin{array}{l}\text { I have tooth or mouth problems } \\
\text { that make it hard for me to eat }\end{array}$ & 0.29 & 0.06 & 2 & 4 \\
\hline 8 & I always have enough money to buy food & $\begin{array}{l}\text { I don't always have enough money } \\
\text { to buy the food I need }\end{array}$ & $0.72^{*}$ & 0.15 & 4 & No $=3$ \\
\hline 9 & I eat alone most of the time & Equivalent & 0.19 & -0.01 & 1 & 2 \\
\hline 10 & $\begin{array}{l}\text { I take } 3 \text { or more different prescribed or over } \\
\text { the counter medicines every day† }\end{array}$ & Equivalent & -0.17 & $0.35^{\star}$ & 1 & 3 \\
\hline $11 a$ & $\begin{array}{l}\text { Without wanting to, I have lost } 5 \mathrm{~kg} \text { in the last } \\
6 \text { months }\end{array}$ & Equivalent & -0.07 & 0.09 & & \\
\hline $11 b$ & $\begin{array}{l}\text { Without wanting to, I have gained } 5 \mathrm{~kg} \text { in the } \\
\text { last } 6 \text { months }\end{array}$ & Equivalent & 0.11 & 0.26 & 2 & 2 \\
\hline 12 & $\begin{array}{l}\text { I am always able to shop, cook and/or feed } \\
\text { myself }\end{array}$ & $\begin{array}{l}\text { I am not always physically able to } \\
\text { shop, cook and/or feed myself }\end{array}$ & 0.16 & 0.15 & 2 & $\mathrm{No}=2$ \\
\hline
\end{tabular}

† Given score if answered three or more to the following question 'During the past 4 weeks, how many different types of medication have you used which were prescribed by a doctor?'.

‡ Based on outcome criteria $\left({ }^{*}, P<0.01\right)$ and expert panel discussion ${ }^{11}$.

$\S$ Adapted from the NSI checklist by an expert panel ${ }^{8}$.

the 14 items for two outcome criteria: three or more nutrients below $75 \%$ of Recommended Dietary Allowance (assessed by 24-hour dietary recall) and fair or poor perceived health. These effect sizes and the opinions of the NSI technical advisory panel were used to eliminate four items and to allocate weights to the remaining items. However, only half of the items used in the checklist were statistically significant predictors of either nutritional inadequacy or perceived health, and the weights given to items did not always correspond with the effect sizes. Despite this, the weights were summed to give a score, and an assessment of the sensitivity (the proportion of people with the condition correctly identified as having the condition), specificity (the proportion of people without the condition correctly identified as not having the condition) and positive predictive values (the proportion of people identified as having the condition who actually have the condition) of various cut-off points was made. A cut-off point of 6 was chosen to define high risk, and the sensitivity, specificity and positive predictive value using this cut-off point were $36 \%, 85 \%$ and $38 \%$ for dietary inadequacy and $46 \%, 85 \%$ and $56 \%$ for perceived health, respectively.

The NSI checklist has been criticised for poor test characteristics, retaining items that are not significantly associated with the outcomes of interest and using outcomes that are neither well-defined pathological states nor have proven treatments ${ }^{12}$. Reuben et al. also question the use of a single 24-hour dietary recall for criterion validity, as it assumes that stability in diet is much greater in older persons than has been demonstrated in the general population ${ }^{6}$. The value of the individual items versus the checklist score has also been debated. A longitudinal study of elderly persons in Boston found that some NSI checklist items (eating alone, problems biting or chewing, difficulties with shopping or cooking, and taking more than three medications) were stronger predictors of mortality than the total score ${ }^{13}$. Despite these limitations, the importance of pursuing the development of nutritional screens and linking malnutrition to subsequent health outcomes has been recognised ${ }^{6}$.

In 1996 an Australian version of the checklist, the Australian Nutrition Screening Initiative (ANSI), was adapted from the NSI checklist by an expert panel who modified the wording and weights of some NSI items to reflect the Australian situation ${ }^{8}$. The ANSI and NSI checklists consist of 12 and 10 items, respectively (Table 1). Five items are equivalent in the two instruments (ANSI items 1, 5, 9, 10 and 11). (After the initial testing phase, two items - having lost $5 \mathrm{~kg}$ or having gained $5 \mathrm{~kg}$ - were combined to form a single item in the $\mathrm{NSI}^{11}$.) For the ANSI scale, one NSI item relating to fruit, vegetables and milk products was split into two (ANSI items 3 and 4), the number of meals eaten per day (ANSI item 2) was increased to three, and an item about the number of cups of fluid consumed per day was added (ANSI item 6). Two negative items in the NSI were changed to positive ones for the ANSI items (ANSI items 8 and 12). 
The NSI and ANSI checklists are being used extensively across the United States and Australia respectively, but there have been no studies comparing the performance of these two scales. There is some concern that the checklists are being used alone for purposes of diagnosis, rather than as awareness tools or prompts for older people and their carers to seek further assessment. Two recent papers, which assessed the NSI as a screening tool, found it to be of limited value in this capacity ${ }^{13,14}$. In Australia, two studies have reported a significant relationship between total ANSI checklist scores and perceived health in older people ${ }^{15,16}$. However, in each of the community samples studied, the ANSI identified more than half of the participants as being at moderate or high risk of malnutrition ${ }^{17}$.

There have been no large, nationally representative studies in Australia to assess eating habits and risk of malnutrition using the ANSI checklist. Neither has the usefulness of the ANSI checklist score, compared with its individual items, been investigated. This paper presents ANSI checklist data for older women (70-75 years) who participated in the baseline survey of the Australian Longitudinal Study on Women's Health (ALSWH) in 1996. It examines the relationships between individual items and various health outcomes (including perceived physical and mental health and health care utilisation) and presents an unweighted method for scoring the ANSI checklist.

\section{Methods}

\section{Study sample}

The sample for this study comprised 12939 women aged 70-75 years (the older cohort of the Australian Longitudinal Study on Women's Health ${ }^{18}$ ). Baseline surveys were conducted in 1996, with follow up in 1999. Participants were randomly selected from women registered on the national Medicare database, which includes almost all people who are resident in Australia, including migrants and refugees. Women living in rural and remote areas were over-sampled. Allowing for inaccuracies in the Medicare database, it has been estimated that $37-40 \%$ of the older women chose to participate in the study ${ }^{19}$. Contact by telephone to encourage participation was not possible because the identities of the selected women remained confidential until they consented to participate. The response rate compares favourably with previous studies that depended solely on postal recruitment, and the respondents in the older cohort have been shown to be broadly representative of the national population of women aged 70-75 years, with some over-representation of married women ${ }^{19}$.

\section{Questionnaire and measures}

The baseline survey of the ALSWH contained items relating to the main themes of the study, including general health and well-being; health service utilisation; smoking and alcohol; weight, exercise and eating; time use and social support. The self-completed postal survey also contained demographic information such as country of birth, marital status, education and living arrangements.

The MOS Short Form Health Survey (SF-36) was included to measure perceived general health and wellbeing $^{20}$. The SF-36 contains 36 items that are scored as eight multi-item scales and two overall summary scores: the Physical Component Summary score (PCS) and the Mental Component Summary score (MCS). The summary scores are compared with norms for the reference population, such that the population average is set at $50^{21}$. Thus for PCS and MCS scores, a score below 50 indicates worse physical or mental health, while a score above 50 indicates better health than the reference population. PCS and MCS are standardised and exhibit normal distributions.

Another measure of health, the number of chronic conditions, was defined by summing positive responses to the questions 'Have you ever been told by a doctor that you have': diabetes, heart disease, hypertension, stroke, thrombosis, asthma, bronchitis/emphysema, osteoporosis or breast, cervical, lung, bowel or skin cancer. The women also recorded the number of times they had consulted a general practitioner, and whether they had been admitted to hospital, in the last year.

Body mass index (BMI) was calculated from height and weight. BMI ranges representing underweight $\left(<20 \mathrm{~kg} \mathrm{~m}^{-2}\right)$, acceptable weight $\left(20-24.9 \mathrm{~kg} \mathrm{~m}^{-2}\right)$ and overweight (25 $\mathrm{kg} \mathrm{m}^{-2}$ or more) were based on the Australian National Health and Medical Research Council guidelines $^{22}$.

The baseline survey contained items from which both the NSI and ANSI scores could be estimated. The ANSI items were used with their exact wording except for the item relating to number of medications taken every day. This was estimated from the answer to the question 'During the past 4 weeks, how many different types of medication have you used which were prescribed by a doctor?' Use of three or more medications was taken as a positive response. Also, having lost or gained weight (item 11) was asked as two separate items, in order to examine the magnitude and direction of their effects in bivariate analyses, although the items were combined in the calculation of the checklist scores.

The individual items and weights used to calculate the ANSI and NSI scores, as defined during their development, are shown in Table 1. Cut-off scores for low, moderate and high nutritional risk were $0-3,4-5$ and 6 or more for $\mathrm{ANSI}^{8}$ and $0-2,3-5$ and 6 or more for $\mathrm{NSI}^{11}$. To explore and evaluate a simpler approach to calculating a risk score, the unweighted ANSI items were also summed to calculate a total summed item score (TSI) (possible range 0 to 12). Ninety-six per cent of the TSI scores were between 0 and 4 , so an upper limit was set at 4 or more. 
ANSI, NSI and TSI scores were set to missing if the answers to more than two items were missing.

\section{Statistical analysis}

To correct for over-sampling of women from rural and remote areas, all responses were weighted for area so that the study population was representative of the Australian population for women of this age group.

With large sample sizes, small differences in means are often statistically significant, although these differences may not be clinically significant. Although no definitive guidelines for clinical significance exist as yet, normative data from the 1995 Australian National Health Survey show that the presence of one serious physical condition (e.g. cancer, heart disease, diabetes, hypertension, asthma, arthritis) results in decreases of physical and mental component scores of 3.3 and 2.1, respectively ${ }^{23}$.

Means were calculated using the MEANS procedure in SAS and the FREQ procedure was used to calculate weighted percentages ${ }^{24}$.

Sensitivity, specificity and positive predictive value were calculated for the moderate- and high-risk cut-off points for the ANSI, NSI and TSI scores. There is no gold standard for defining malnutrition in an epidemiological setting, so greater than six general practitioner visits and self-reported BMI outside the acceptable range (20$24.9 \mathrm{~kg} \mathrm{~m}^{-2}$ ) were used as surrogate measures of malnutrition.

\section{Results}

The demographic and health characteristics of the women have been reported elsewhere ${ }^{19}$. Briefly, the majority (73\%) of the women were Australian born, more than half (55\%) were married and one-third were widowed. Thirtyfive per cent of the women lived alone and, of these, three-quarters were widowed. While $34 \%$ had no formal educational qualifications, $51 \%$ had completed secondary school and the remainder had post-school qualifications.

Thirty-two per cent of the women made more than six visits to a general practitioner in the previous year and $28 \%$ felt their health was only fair or poor. Twenty-four per cent of the women reported having two or more chronic conditions, and $23 \%$ had been admitted to hospital in the previous year. Fewer than half the women were in the healthy weight range, with $9 \%$ underweight and $47 \%$ overweight.

The frequency of responses to each of the ANSI items is shown in Table 2. Almost half the women took three or more prescribed medications, more than one-third ate alone most of the time and more than a quarter had changed their diet because of an illness. The NSI and the ANSI identified approximately half of the women to be at low nutritional risk. Using a TSI score of 0 or $1,46 \%$ of women were identified as 'low-risk'. However, ANSI defined $30 \%$ of the women to be at high nutritional risk,
Table 2 Prevalence for individual ANSI items, estimated checklist scores for ANSI and NSI, and TSI (sum of unweighted items)

\begin{tabular}{|c|c|c|c|}
\hline \multicolumn{3}{|l|}{ Item } & Prevalence* $(\%)^{*}$ \\
\hline \multicolumn{3}{|c|}{ Changed diet due to illness } & 27 \\
\hline \multicolumn{3}{|c|}{ Do not eat at least 3 meals a day } & 8 \\
\hline \multicolumn{3}{|c|}{ Do not eat fruit or vegetables most days } & 3 \\
\hline \multicolumn{3}{|c|}{ Do not eat dairy products most days } & 13 \\
\hline \multicolumn{3}{|c|}{ Have 3 or more alcoholic drinks a day } & 6 \\
\hline \multicolumn{3}{|c|}{ Do not have 6 to 8 cups of fluid most days } & 11 \\
\hline \multicolumn{3}{|c|}{ Have teeth, mouth, swallowing problems } & 8 \\
\hline \multicolumn{3}{|c|}{ Do not have enough money to buy food } & 4 \\
\hline \multicolumn{3}{|c|}{ Eat alone most of the time } & 39 \\
\hline \multicolumn{3}{|c|}{ Take 3 or more prescribed medications } & 45 \\
\hline \multicolumn{3}{|c|}{ Lost $5 \mathrm{~kg}$ without wanting to } & 6 \\
\hline \multicolumn{3}{|c|}{ Gained $5 \mathrm{~kg}$ without wanting to } & 10 \\
\hline \multicolumn{3}{|c|}{ Not always able to shop, cook, feed myself } & 6 \\
\hline \multicolumn{4}{|c|}{ ANSI score (range 0-29) } \\
\hline \multicolumn{3}{|c|}{ 0-3 Low risk } & 48 \\
\hline \multirow{2}{*}{$\begin{array}{l}4-5 \\
\geq 6\end{array}$} & Moderate risk & & 23 \\
\hline & High risk & & 30 \\
\hline \multicolumn{4}{|c|}{ NSI score (range 0-21) } \\
\hline \multicolumn{3}{|c|}{ 0-2 Low risk } & 54 \\
\hline \multirow{2}{*}{$\begin{array}{l}3-5 \\
\geq 6\end{array}$} & Moderate risk & & 33 \\
\hline & High risk & & 13 \\
\hline \multicolumn{4}{|c|}{ TSI score (range 0-12) } \\
\hline \multirow{2}{*}{$\begin{array}{l}0 \\
1\end{array}$} & No items & & 17 \\
\hline & One item $\}$ & LOW risk & 29 \\
\hline \multirow{3}{*}{$\begin{array}{l}2 \\
3 \\
\geq 4\end{array}$} & Two items & 'Moderate' risk & 26 \\
\hline & Three items $\int$ & ivivuelate $110 \mathrm{~h}$ & 16 \\
\hline & Four or more items & ‘High’ risk & 12 \\
\hline
\end{tabular}

* Weighted to allow for over-sampling of women living in rural and remote areas.

compared with 13\% using NSI and 12\% using a cut-off of 4 or more for high TSI. Eighty-nine per cent of women with high TSI were also in the high NSI group. In comparison, approximately $40 \%$ of women in the high ANSI group were in the high NSI and TSI groups. For $2.4 \%$ of women, checklist scores were not calculated due to missing data.

The most common checklist items for women with 'high-risk' ANSI, NSI and TSI scores were: taking three or more medications (71-80\%); changing their diet due to illness (54-66\%); and eating alone (55-66\%).

The SF-36 physical and mental health component scores for women who answered 'yes' and 'no' to each ANSI item are shown in Table 3. Five of the items were associated with both poorer physical and mental health: change of diet due to illness; teeth, mouth or swallowing problems; taking three or more medications; losing $5 \mathrm{~kg}$ without wanting to; and the inability to shop, cook or feed herself. Women reporting any of these items were also more likely to have more than two chronic conditions and to use health services more often (more than six visits to a general practitioner and admission to hospital in the previous year) (data not shown). Mean mental health component scores were at least 2.1 points lower for women who ate less than three meals a day, who did not eat fruit or vegetables or dairy products most days and who did not have enough money to buy food. Three items were not associated with differences in physical or mental component scores: three or more alcoholic drinks per day; fewer than six to eight cups of 
Table 3 Mean SF-36 physical health component score (PCS) and mental health component score (MCS) for individual ANSI items $†$

\begin{tabular}{|c|c|c|c|c|}
\hline \multirow[b]{2}{*}{ ANSI item } & \multicolumn{2}{|c|}{ Mean PCS } & \multicolumn{2}{|c|}{ Mean MCS } \\
\hline & Riskł & No risk & Riskł & No risk \\
\hline Changed diet due to illness & $46.2^{*}$ & 51.5 & $48.4^{*}$ & 50.9 \\
\hline Do not eat at least 3 meals a day & 48.9 & 50.1 & $47.2^{\star}$ & 50.4 \\
\hline Do not eat fruit or vegetables most days & 48.0 & 50.1 & $44.8^{*}$ & 50.3 \\
\hline Do not eat dairy products most days & 49.2 & 50.1 & $48.4^{*}$ & 50.5 \\
\hline Have 3 or more alcoholic drinks a day & 51.4 & 49.9 & 49.7 & 50.2 \\
\hline Do not have 6 to 8 cups of fluid most days & 49.6 & 50.1 & 48.6 & 50.4 \\
\hline Have teeth, mouth, swallowing problems & $44.4^{*}$ & 50.5 & $45.6^{*}$ & 50.6 \\
\hline Do not have enough money to buy food & 48.3 & 50.1 & $47.5^{\star}$ & 50.3 \\
\hline Eat alone most of the time & 50.0 & 50.0 & 49.5 & 50.6 \\
\hline Take 3 or more prescribed medications & $45.6^{\star}$ & 53.6 & $48.7^{*}$ & 51.4 \\
\hline Lost or gained $5 \mathrm{~kg}$ without wanting to & $46.0^{\star}$ & 50.7 & $47.2^{*}$ & 50.7 \\
\hline Lost $5 \mathrm{~kg}$ without wanting to & $44.6^{*}$ & 50.3 & $44.8^{*}$ & 50.6 \\
\hline Gained $5 \mathrm{~kg}$ without wanting to & $46.9^{*}$ & 50.4 & 48.6 & 50.5 \\
\hline Not always able to shop, cook, feed myself & $41.3^{\star}$ & 50.5 & $43.7^{*}$ & 50.5 \\
\hline
\end{tabular}

* Means for risk versus no risk likely to be clinically significantly different ${ }^{23}$.

$\dagger$ Weighted to allow for over-sampling of women living in rural and remote areas.

$\ddagger$ Risk = answered 'yes' to this item.

fluid; and eating alone most of the time. Women who reported involuntary weight gain of $5 \mathrm{~kg}$, taking three or more medications, being unable to shop, cook or feed themselves or not eating fruit or vegetables most days were more likely to be overweight (data not shown). Women who had lost $5 \mathrm{~kg}$ involuntarily were more likely to be underweight.

There were decreases in mean physical and mental health component scores, increases in number of chronic conditions and health service utilisation with each extra checklist item reported (data not shown). Women identified as at high risk by NSI had similar physical and mental health component scores and reported similar rates of underweight and other health outcomes to women with high TSI. All health measures deteriorated as ANSI, NSI and TSI scores increased. However, the women in the high NSI and TSI groups appeared to have worse health than those in the high ANSI group (Table 4).

Sensitivities were poor for the high cut-off point on all checklists. The sensitivities were better when moderate cut-off points were used. However, the positive predictive values were worse, particularly for GP visits (Table 5).

\section{Discussion}

Several studies, each with relatively small samples, have documented the prevalence of the individual ANSI or NSI items in community dwelling men and women in Australia $^{15,16}$ and elsewhere ${ }^{11,13,14}$. Data from the Australian Longitudinal Study on Women's Health provided an opportunity to investigate these items in a large, nationally representative sample of women aged 70-75 years. In this community sample of 12939 women, the most common responses to these checklist items were taking three or more medications per day, eating alone most of the time and change of diet due to illness. These results are consistent with those found in other studies. In contrast, this and other Australian studies have demonstrated that eating few fruit, vegetables or milk products is far less common in Australia than elsewhere ${ }^{11,13-16}$.

Table 4 Mean physical and mental health component scores (PCS and MCS), chronic conditions, health service utilisation and weight by categories of nutrition score for ANSI, NSI and TSI†

\begin{tabular}{|c|c|c|c|c|c|c|c|c|c|}
\hline & & & $\begin{array}{c}\text { PCS } \\
\text { (mean) }\end{array}$ & $\begin{array}{c}\text { MCS } \\
\text { (mean) }\end{array}$ & $\begin{array}{c}>6 \text { general } \\
\text { practitioner visits } \\
(\%)\end{array}$ & $\begin{array}{l}>2 \text { chronic } \\
\text { conditions } \\
(\%)\end{array}$ & $\begin{array}{l}\text { Admitted to } \\
\text { hospital } \\
(\%)\end{array}$ & $\begin{array}{c}\text { Underweight } \\
\left(\mathrm{BMI}<20 \mathrm{~kg} \mathrm{~m}^{-2}\right) \\
(\%)\end{array}$ & $\begin{array}{c}\text { Overweight } \\
\left(\mathrm{BMI} \geq 25 \mathrm{~kg} \mathrm{~m}^{-2}\right) \\
(\%)\end{array}$ \\
\hline \multicolumn{10}{|c|}{ ANSI risk score (range 0-29) } \\
\hline $0-3$ & Low & $(n=6186)$ & 53.2 & 52.2 & 18 & 14 & 16 & 8 & 43 \\
\hline $4-5$ & Moderate & $(n=2818)$ & 48.8 & 50.0 & 37 & 27 & 25 & 7 & 50 \\
\hline$\geq 6$ & High & $(n=3626)$ & 45.7 & 47.0 & 51 & 39 & 33 & 10 & 50 \\
\hline \multicolumn{10}{|c|}{ NSI risk score (range $0-21$ ) } \\
\hline $0-2$ & Low & $(n=7028)$ & 52.5 & 51.9 & 21 & 16 & 17 & 8 & 44 \\
\hline $3-5$ & Moderate & $(n=4078)$ & 47.8 & 49.1 & 42 & 33 & 27 & 8 & 50 \\
\hline$\geq 6$ & High & $(n=1558)$ & 44.9 & 45.4 & 51 & 39 & 38 & 11 & 48 \\
\hline \multicolumn{10}{|c|}{ TSI risk score (range $0-12$ ) } \\
\hline $0-1$ & Low & $(n=6079)$ & 53.2 & 52.2 & 18 & 14 & 16 & 8 & 43 \\
\hline $2-3$ & Moderate & $(n=5189)$ & 48.0 & 49.4 & 41 & 31 & 26 & 8 & 50 \\
\hline$\geq 4$ & High & $(n=1362)$ & 44.2 & 44.9 & 55 & 44 & 41 & 12 & 49 \\
\hline
\end{tabular}

† Weighted to allow for over-sampling of women living in rural and remote areas. 
Table 5 Diagnostic statistics for medium and high cut-off points for ANSI, NSI and TSI†

\begin{tabular}{|c|c|c|c|c|}
\hline & \multicolumn{2}{|c|}{$>6$ general practitioner visits (\%) } & \multicolumn{2}{|c|}{$\mathrm{BMI}<20 \mathrm{~kg} \mathrm{~m}^{-2}$ or $\geq 25 \mathrm{~kg} \mathrm{~m}^{-2}(\%)$} \\
\hline & Moderate cut-off point & High cut-off point & Moderate cut-off point & High cut-off point \\
\hline \multicolumn{5}{|l|}{ ANSI } \\
\hline Sensitivity & 73 & 47 & 56 & 32 \\
\hline Specificity & 58 & 79 & 52 & 74 \\
\hline Positive predictive value & 45 & 51 & 59 & 60 \\
\hline \multicolumn{5}{|l|}{ NSI } \\
\hline Sensitivity & 64 & 21 & 48 & 14 \\
\hline Specificity & 63 & 91 & 58 & 88 \\
\hline Positive predictive value & 45 & 51 & 59 & 59 \\
\hline \multicolumn{5}{|l|}{ TSI } \\
\hline Sensitivity & 74 & 20 & 56 & 12 \\
\hline Specificity & 57 & 92 & 51 & 90 \\
\hline Positive predictive value & 44 & 55 & 59 & 61 \\
\hline
\end{tabular}

† Weighted to allow for over-sampling of women living in rural and remote areas.

Differences in the wording of, and/or estimation of positive responses to, some ANSI and NSI items make comparison with previous studies difficult. Firstly, Sahyoun et $a l .{ }^{13}$ and de Groot et $a l .{ }^{14}$ estimated fruit, vegetable and milk consumption from food frequency data. Secondly, the item about number of meals eaten per day scores a positive response in ANSI if less than three meals are eaten and in NSI if less than two meals are eaten. Thirdly, in the present study, women were asked how many medications they had taken in the last four weeks rather than the number taken per day. Despite this, the prevalence of these last two items was similar in all studies.

Few studies have examined the relationship between individual items in these scales and health. In this study, five items were found to be strongly related to perceived general health and well-being, number of chronic conditions and health care utilisation. These were: the woman's inability to shop, cook or feed herself; having teeth, mouth or swallowing problems; taking three or more medications per day; change of diet due to illness; and involuntary change in weight. Sahyoun et al. also found the first three of these items, as well as eating meals alone, to be positively associated with mortality and to have better predictive value than the overall NSI score for men and women ${ }^{13}$. In Posner et al.'s analysis, taking three or more medications and change of diet were the best predictors of perceived health. This study may not, however, have had the power to detect the importance of other items and the measure of health was based on a single question ${ }^{11}$. It appears that the real value of the checklist as a predictive tool may lie with the individual items.

In this sample of women, three of the items - eating alone; alcohol consumption; and fluid consumption - did not appear to be related to physical or mental health, suggesting that these items may be redundant for women. However, since men are more likely to have three or more

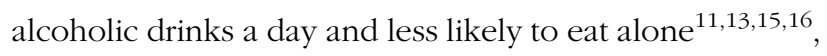
these items may have more relevance in studies that include men.

Involuntarily losing $5 \mathrm{~kg}$ is associated with worse perceived physical and mental health, more than two chronic conditions and higher health care utilisation. As the effects of involuntary weight loss and weight gain differ, this study has demonstrated the value of monitoring the magnitude and direction of weight change.

In this study, the recommended cut-off points of 6 for NSI and ANSI scores identified $13 \%$ and $30 \%$ of women to be at high nutritional risk, respectively, which would suggest that the changes made to the NSI weightings for the ANSI may be inappropriate. The NSI and ANSI were originally established to increase public awareness of the importance of nutrition in the elderly, but the high proportion of the elderly defined as being 'at risk' by the ANSI is a cause for concern. It may result in unnecessary stress for elderly people and place excess burden on the health care system through self-referrals. The unweighted TSI score offers a simpler way to score the ANSI checklist, and a score of 4 or more identifies the majority of the women in the high NSI group.

Based on values for sensitivity, specificity and positive predictive values, none of these checklists is particularly good at identifying malnutrition in this cross-sectional study. At least $40 \%$ of women would be falsely identified as being at risk of malnutrition. However, the ANSI and NSI are widely used. The longitudinal nature of the present study will allow the value of the continued use of these checklists to be studied.

In the interim, these cross-sectional results show that women in the high-risk groups for ANSI, NSI and TSI were more likely to have poorer levels of physical and mental health and higher health service utilisation. Whether this is due to nutrition or their underlying medical conditions is not clear. Further, whether women in poor health are more at risk of malnutrition or whether 
poor nutrition leads to a decline in health is also unclear. These relationships can only be determined by longitudinal studies that include a measure of nutrition.

No studies have demonstrated that nutrition risk screening and intervention lead to better health outcomes ${ }^{6}$. While the ALSWH currently has no nutritional data, an advantage of the study is that the predictive value of the checklist items, as well as of the ANSI, NSI and TSI scores, can be examined in terms of health-related quality of life, general practitioner visits, hospitalisation and mortality. Hence the value of continuing the widespread use of nutrition screening checklists in the community, and the potential impact of interventions targeted to highrisk groups, can be assessed.

\section{Acknowledgements}

The Australian Longitudinal Study on Women's Health, which was developed by groups of interdisciplinary researchers at the Universities of Newcastle and Queensland, is funded by the Commonwealth Department of Health and Aged Care. We thank all participants for their valuable contribution to this project.

The work described in this paper was approved by the Human Research Ethics Committee of the University of Newcastle.

\section{References}

1 Stableforth PG. Supplement feeds and nitrogen and calorie balance following femoral neck fracture. Br. J. Surg. 1986; 73: 651-5.

2 Sullivan DH, Walls RC, Lipschitz DA. Protein-energy undernutrition and the risk of mortality within 1 year of hospital discharge in a select population of geriatric rehabilitation patients. Am. J. Clin. Nutr. 1991; 53: 599-605.

3 Nyswonger GD, Helmchen RH. Early enteral nutrition and length of stay in stroke patients. J. Neurosci. Nurs. 1992; 24: $220-3$.

4 Ferguson RP, O'Connor P, Crabtree B, Batchelor A, Mitchell J, Coppola D. Serum albumin and prealbumin as predictors of clinical outcomes of hospitalised elderly nursing home residents. J. Am. Geriatr. Soc. 1993; 41: 545-9.

5 Potter J, Klipstein K, Reilly JJ, Roberts M. The nutritional status and clinical course of acute admissions in a geriatric unit. Age and Ageing 1995; 24: 131-6.

6 Reuben DB, Greendale GA, Harrison GG. Nutrition screening in older persons. J. Am. Geriatr. Soc. 1995; 43: 415-25.

7 Lehmann AB. Nutrition in old age: an update and questions for future research: part 1. Rev. Clin. Gerontol. 1991; 1: 13545.

8 Lipski PS. Australian Nutrition Screening Initiative. Aust. J. Ageing 1996; 15: 14-7.

9 Goodwin JS. Social, psychological and physical factors affecting the nutritional status of elderly subjects: separating cause and effect. Am. J. Clin. Nutr. 1989; 50: 1201-9.

10 White JV, Dwyer JT, Posner BM, Ham RJ, Lipschitz DA, Wellman NS. Nutrition Screening Initiative: development and implementation of the public awareness checklist and screening tools. J. Am. Diet. Assoc. 1992; 92: 163-7.

11 Posner BM, Jette AM, Smith KW, Miller DR. Nutrition and health risks in the elderly: the nutrition screening initiative. Am. J. Public Health 1993; 83: 972-8.

12 Rush D. Evaluating the nutrition screening initiative. Am. J. Public Health 1993; 83: 944-5.

13 Sahyoun NR, Jacques PF, Dallal GE, Russell RM. Nutrition screening initiative checklist may be a better awareness/ educational tool than a screening one. J. Am. Diet. Assoc. 1997; 97: 760-4.

14 de Groot LCPGM, Beck AM, Schroll M, van Staveren WA. Evaluating the DETERMINE your nutritional health checklist and the mini nutritional assessment as tools to identify nutritional problems in elderly Europeans. Eur. J. Clin. Nutr. 1998; 52: 877-83.

15 Cobiac L, Syrette JA. What is the nutritional status of older Australians? Proc. Nutr. Soc. Aust. 1995; 19: 139-45.

16 Burge K, Gazibarich B. Nutritional risk among a sample of community-living elderly attending senior citizens' centres. Aust. J. Nutr. Diet. 1999; 56: 137-43.

17 Cobiac L, Richardson A, Mohr P, Syrette J. Validation of a nutrition screening tool for the elderly in Australia [abstract]. In: Proceedings of the 16th Congress of the International Association of Gerontology Adelaide, South Australia, 1923 August 1997. Bedford Park, SA: 1997 World Congress of Gerontology, Inc., 1997.

18 Brown WJ, Bryson L, Byles JE, et al. Women's Health Australia: recruitment for a national longitudinal cohort study. Women and Health 1998; 28: 23-40.

19 Brown WJ, Dobson AJ, Bryson L, Byles JE. Women's Health Australia: on the progress of the main cohort studies. $J$. Women's Health 1999; 8: 681-8.

20 Ware JE, Kosinski M, Keller SD. SF-36 Physical and Mental Health Summary Scales: A User's Manual. Boston, MA: The Health Institute, New England Medical Centre, 1994.

21 Mishra G, Schofield M. Norms for the physical and mental component summary scores of the SF-36 for young, middle and older Australian women. Qual. Life Res. 1998; 7: 215220

22 National Health and Medical Research Council. Report of the One Hundredth Session. Canberra: Australian Government Publishing Service, 1985.

23 Australian Bureau of Statistics. National Health Survey Australia, 1995: SF-36 Population Norms. Canberra: Australian Government Publishing Service, 1997.

24 SAS Institute, Inc. SAS/STAT User's Guide, Version 6, Volume 1, 4th ed. Cary, NC: SAS Institute, Inc., 1989. 